\title{
Comparison Between the Effect of Motorcycle Safety Campaign Using Animated Video and Live Action Video-A Preparation Stage
}

\author{
Leksmono Suryo Putranto ${ }^{1, *}$, and Rostiana ${ }^{2}$ \\ ${ }^{1}$ University of Tarumanagara, Department of Civil Engineering, Jalan Letjen S. Parman 1, Jakarta \\ 11440 , Indonesia \\ ${ }^{2}$ Univiversity of Tarumanagara, Faculty of Psychology, Jalan Letjen S. Parman 1, Jakarta 11440, \\ Indonesia
}

\begin{abstract}
Hypothetically, traffic safety campaign using animated video and live action video will get different result. This paper discuss the preparation stage of a study to compare between the effect of motoryccle safety campaign using animated video and live action video.There were some activities on this stage. Firstly was the selection of three live action videos from nine live action videos available from previous study. This was followed by the development of thre animated videos based on these three live action videos. There will be also development of completely new three animated videos. These three brand new videos were developed in animated version because they will be too dangerous to create live action videos of this version, e.g. to describe motorcyclist risky behaviour such as motorcycle travelling in opposite direction. A hundred students from four universities in Indonesia will be asked to observed different type of videos and fill some questionnaires to compare between the effect of motoryccle safety campaign using animated video and live action video.
\end{abstract}

\section{Introduction}

As a result of uncontrolled development of Indonesian cities land use and lack of seamless public transport system, severe congestions were happened daily. People should keep conducting their duties and therefore they need to travel every day. Driving a car will trap people in long traffic queues. Therefore they purchase motorcycle which perceived to travel them faster to the diestination with the ability to use small gap to avoid congestion [1].

In authors previous research the effect of various motorcyclist safety campaign media (audio, still picture and video) to the attitude change was evaluated. Although all type of campaign media have similar short term positive effects on attitudes change, the effect of video was slightly higher [1]. Persumably, video can be effectively change motorcycle rider behaviours into better attitudes because it can deliver stronger messages as a combined effect of moving pictures, audio messages, text messages, animations, sound effects and musical illustration supporting each other.

* Corresponding author: lexy_putranto@yahoo.co.id 
As some campaign messages (such as motorycle traveling in opposite direction) are to dangerous to be developed in live action videos, the authors decided to develop such campaign messages in animated videos. This present research will compare the effect of watching animated and live action motorcycle safety videos to motorcyclists attitudes.

\section{Related works}

Putranto and Rostiana [1] conducted a research on 107 student respondents from University of Udayana (Denpasar), University of Tanjungpura (Pontianak), Institut Teknologi Sepuluh Nopember (Surabaya) and University of Andalas (Padang). All 22 motorcycling related behaviours daily conducted by the respondents can be changed into better attitudes after observing pictures and/ or hearing audios and/ or watching videos and/ or watching testimonial videos. All changes were positive changes and statistically significant at 0.05 significant level

Furthermore Putranto and Rostiana [1] stated that V9, a three minutes long video containing various messages can change 11 motorcycling related behaviours into better motorcycling related attitudes. Meanwhile P2, a picture about children helmet can not change any motorcycling related behaviour into better attitude. It can also be seen that the power of pictures to change motorcycling related behaviours into better motorcycling related attitudes were limited, whilst the power of audios, videos and testimonial videos to change motorcycling related behaviours into better motorcycling related attitudes were quite many. As stated before, video can be effectively change motorcycle rider behaviours into better attitudes because of its combined effect of different elements supporting each other.

Colclough [2] defined animation as the art of drawing sketches and objects and then showcasing them in series of frames, making it look like the images are moving. Animated videos tend to used in any from of explainer videos used to educate and inform the viewers. On the contrary, live action video is a recording of either still or moving objects. Live action videos can refer to both cinematography that does not make use of animations. Animated videos tent to be less expensive. However costs can still amount due to all scripting, illustration, animatoins, editing and sound effects. Animation however might take longer time to develop if it is developed from scratch. Therefore the use of library of pre made one can speed up the process. Creating human emotion using animation is not easy, but one advantage of using animation is it can explain tricky idea in faster manner than live action video.

\section{Material and method}

This paper is prepared based on the third year of a three years research on Indonesian motorcyclists risky behaviour. In the first year research, an Indonesian Motorcycle Rider Behaviour Questionnaire (MRBQ) was developed. The Indonesian MRBQ was consists of 38 question items categorized into 6 subscales, i.e. traffic errors, control errors, speed violations, traffic violations, safety violations and stunts [3].

In the second year research, effect of different type of traffic safety campaign media to motorcyclists attitude change was observed and reported in [4] and [1]. There were several different campaign media observes, i.e. still pictures in the form of poster, audios in the form of radio advertisement, short live action videos in the form of television/ movie adversitsement and testimonial videos in the form of television/ movie advertisements. 
The third year is still about the effect of different type of traffic safety campaign media to motorcyclists atitude change, but specifically on the difference of live action video and animated video effects. The third year research methodology is presented in Fig 1.

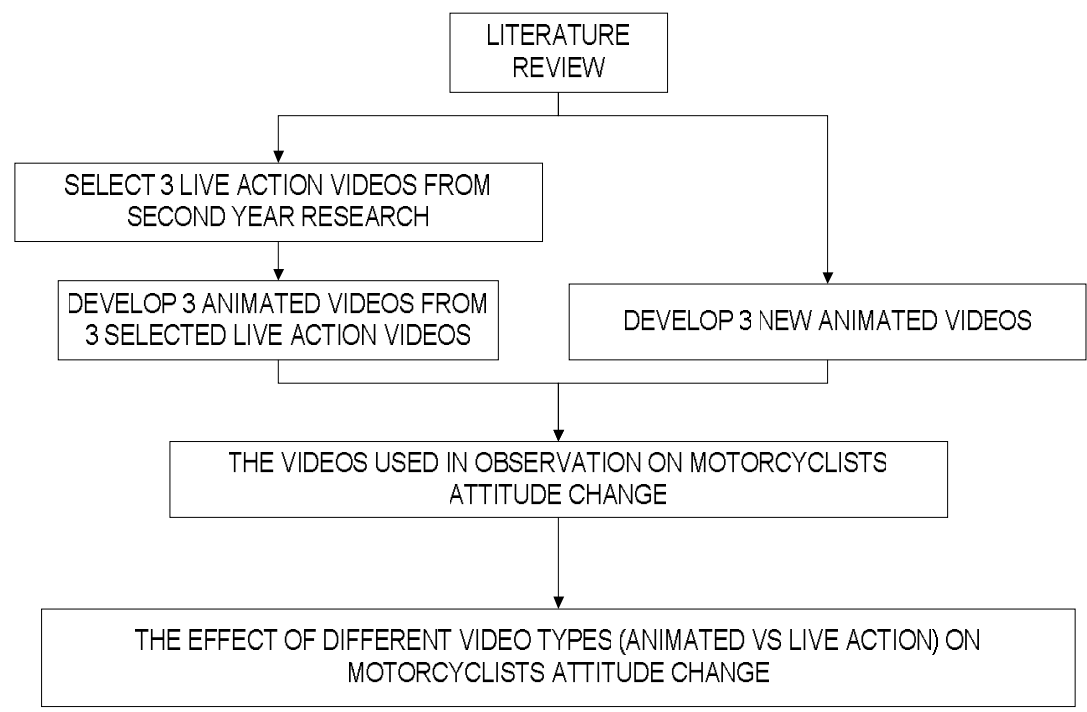

Fig. 1. Third year research methodology

In the second year research, nine live action videos were observed by the respondents. The theme of those videos were:

- Helmet for Children

- Overloaded Motorcycle

- Riding Safety Equipments

- My First Helmet

- Standard Helmet

- Risky Rides

- Never Come Back (Underage Rider)

- For Love (Riding Safety Euipments)

- Practical Motorcycling Guidance

In this third year research, the author select three of them based on two considerations, i.e.:

- Variation on campaign message delivered.

- Complication of actualizing the scene in live action video, e.g. risky actions

After considering the above criteria, the three chosen videos were:

- Helmet for Children

- Overloaded Motorcycle

- Never Come Back (Underage Rider)

The following were the synopsis of the selected videos:

- Helmet for Children (30 seconds):

A father carried his little daughter with his motorcycle. The mother has remined her husband to equipped the child with helmet and jacket but he neglected her and argued that it will be a short trip only. Few seconds later there was a motorcycle 
accident suffered by the father and daughter. The kid was unconscious after her had hit the road pavement, as she did not wear a helmet.

- Overloaded Motorcycle (30 seconds):

A fruit trader has just received an order to deliver some fruits. He thought that if he brought as many fruits as he can at once, he will get substantial benefit. Her wife disagree when she saw her husband trying to brought every single ordered fruits at once. The fruit trader shouted to other road users to move aside and give him a way. As a result the he lost his balance and the fruits fell apart.

- Never Come Back (Underage Rider) (60 seconds):

A father was so proud of his son academic achievement in a junior high school. So he gave his son a motorcycle as a present. The young boy rode the motorcycle and almost hit other road users until finally he hit a car. The video ended with a scene showing that his son who badly injured should use a wheelchair.

When transfering these live action videos into animated videos certain aspects were considered, among others:

- Although it is imposible to recreate every single details in live action videos into animated scenes, but all efforts should be done to recreate the scenes as complete as possible.

- To develop smooth movement of each characters in the animated videos are too costly and time consuming, but any simplification of movement should guarantee that no awkward movement of any main characters in the videos are allowed

- Dialects of the main characters should be as similar as possible with the live action videos to avoid differences in cultural senses.

Therefore animated videos were produced by professionals in animation. Their services include the followings:

- The production of story board. This is more comprehensive compare to a story line. Story board consists of serial of cartoon pictures that can be used to describe the story in multimedia softwares [5].

- The choice of 2D and 3D assests. It is time consuming for animator to create 2D and $3 \mathrm{D}$ assests from scratch. Usually they use either available free 2D and 3D libraries or the paid ones.

- Animating.

- Motion Graphics, i.e. pieces of digital footage or animation which create the illusion of motion or rotation, and are usually combined with audio for use in multimedia projects.

- Composing.

- Voice Over, i.e. a production technique where a voice - that is not part of the narrative) - is used in a radio,television production, filmmaking, theatre, or other presentations. The voice-over is read from a script and may be spoken by someone who appears elsewhere in the production or by a specialist voice talent.

- Editing and Scoring as a part of post production, to finalize the animated video.

Besides recreating the three live action videos from the second year research, a fully new animated videos will also be produced. Again, these videos would be too dangerous if actualized in live action videos. The followings are the synopsis of the videos:

- Motorcyle Flowing in the Opposite Directions (60 seconds). A woman was riding a motorcycle in the opposite of the determined direction in a four lanes-two ways devided road. She did that because she live faraway (more than $2 \mathrm{~km}$ ) from the 
nearest u-turn. Moreover after that, she should make another u-turn located $3.5 \mathrm{~km}$ from the first u-turn. Her daily destination was ony $1 \mathrm{~km}$ from her residence. There was no police officer on duty nearby the site of this traffic law violation. At that time $(8$ a.m.) the weather was fine and the traffic flow was rather high but still flowing. Suddenly a car was emerge from a small side road perpendicular to the main road. The visibility of this access was insufficient due to the existence of $2 \mathrm{~m}$ high solid wall. As a result the woman was hit and squashed by the car.

- Motorcycle with Overloaded Passengers and Luggages (30 seconds). A man carried his wife and their five years old son on a trip to their hometown to celebrate a yearly religious event. They brought many luggages by installing a wooden board at the back of the morcycle. When they almost reach their destination, the man felt exhausted, so he accelarated the motorcycle and reaching very hgh speed. It was around noon. As he became more exhausted, he lost his balance and as a result they fell into paddy field in the roadside.

- Motorcycle flowing on Sidewalk and Pedestrian Bridge (30 detik). A young man rode a motorcyle in a heavy traffic of an afaternoon peak hour. To avoid congestion he rode the mororcycle on a sidewalk and when he intended to make a u-turn he utilized a pedestrian bridge. Shortly after leaving the pedestrian bridge, he rode the motorcycle in the sidewalk in a quite high speed. As his vision was obstructed by the pedestrian bridege piers, it was to late for him to realize that there were groups of a highschool students walking on the opposite direction of the sidewalk. As a result he hit two of the students until they are heavily injured.

Based on the previous experience in [1] sample size of about a hundred students were sufficient for the purpose of the study. As the respondents were all undergradute students with similar age and similar cognitive level, increase the number of respondents might be meaningless. Therefore, in this study about a hundred students from 4 universities in Indonesia will be asked to:

i) Fill selected items in Indonesian MRBQ.

ii) Watch 3 live action videos and then fill another qustionnare to identify whether the live action videos are able to generate attitude change.

iii) Watch 3 animated videos (that recreate scenes in live action videos) and then fill another qustionnare to identify whether the animated videos are able to generate attitude change.

iv) Watch 3 brand new animated videos and then fill another qustionnare to identify whether the brand new animated videos are able to generate attitude change.

v) Provide evaluation on the difference of the 3 live action videos and 3 animated videos that recreate scenes in live action videos in terms of (a) the power to deliver overall message of the traffic safety campaign theme The power to deliver overall message of the traffic safety campaign theme (b) the missing scenes (c) The missing main characters (d) The inappropriate animated scenes to recreate live action scenes (e) Inappropriateness of main characters dialects (f) Inappropriateness of musical illustration.

vi) Provide evaluation on 3 brand new animated videos when compared to their synopsis in terms of (a) the power to deliver overall message of the traffic safety campaign theme (b) the missing scenes (c) the missing main characters (d) inappropriateness of main characters dialects (e) Inappropriateness of musical illustration.

A Likert Scale of 1 to 5 is to be used to both the selected itmes of Indonesian MRBQ and other questionnaires to identify any possible attitude change after watching different type of videos. T-test of mean difference between responses from baseline survey (using 
the selected items of Indonesian MRBQ) and after intervention survey (after watching different type of videos) will be conducted with 0.05 significant level.

\section{Future works}

The animated videos production was still on progress, so the main survey has not been conducted yet. However in our hypothesis the general expected result will be (i) As found in the second year research, a short term attitude change will be shown by most of respondents after watching the 3 live action videos. (ii) Similar results might happen after watching the 3 animated videos that recreate 3 live action videos. However compare to point number 1 the attitude change might be marginally lower in terms of mean diffierence of responses. (iii) Similar results might also happen after watching 3 brand new animated videos. However compare to point number 2 the attitude change might be marginally lower in terms of mean diffierence of responses. (iv) The respondents might satisfy with the power of animated videos to deliver overall message of the traffic safety campaign. However they might critically pointed out some inappropriateness. The defficiencies might more apparent in 3 brand new animated videos as the scenes and the characters should be created almost from scratch.

\section{Concluding remarks}

This is stil an ongoing research. The author hope to finish the research by the end of 2016 . Final findings will be reported in further publication. Preliminary analysis shows that short term attitude change were shown by most respondents after watching live action videos. Similar effect was found after watching animated videos. I acknowledge the Ministry of Research, Technology and Higher Education who provide the fund for this three years research on risky behaviour of Indonesian motorcyclist

\section{References}

[1] L.S. Putranto, Rostiana. Proceeding of $10^{\text {th }}$ Asia Pacific Conference on Transportation and Environment, (2016) (to be published soon)

[2] L. Colclough, Animated video vs live action video: Which one shoud you choose? (2016), retrieve on 20 September 2016 from https://www.moovly.com/blog/animatedvideo-vs-live-action-video-which-one-should-you-choose

[3] L.S. Putranto, N.L.P.E. Setyarini, Rostiana, R. Bunawan, Proceeding of $17^{\text {th }}$ International Symposium of Indonesian Inter-University Transportation Studies Forum, 2(1), 1038-1044 (2014)

[4] L.S. Putranto, Rostiana, Proceeding of Conference of ASEAN Road Safety, 369-373 (2015)

[5] D. Prasetyo, Pengertian Storyboard, (2016), retrieve on 20 September 2016 from http://www.davidprasetyo.com/2015/11/ pengertian-storyboard.html (2015) 